\title{
Evaluating Value of Natural Landscapes in China
}

\author{
XIAO Yi ${ }^{1}$, CHENG Cheng ${ }^{1}$, YANG Wu ${ }^{2}$, OUYANG Zhiyun ${ }^{1}$, RAO Enming ${ }^{1}$ \\ (1. State Key Laboratory of Urban and Regional Ecology, Research Center for Eco-Environmental Sciences, Chinese Academy of Sci- \\ ences, Beijing 100085, China; 2. Conservation International, 2011 Crystal Drive Suite 500, Arlington, VA 22202, USA)
}

\begin{abstract}
Natural landscapes consist of the natural substances, environment, and phenomena, all of which provide many benefits to people, including a sense of place, sightseeing, relaxing, and recuperating. However, the economic value of natural landscapes has only been recognized in recent decades, and the resulting large-scale decline and degradation of ecosystems now severely threatens the sustainable provision of their services to society. There is an emerging consensus that natural capital should be incorporated into the current socioeconomic accounting system. Many studies valuated natural resources at local and regional scales, but there are very few empirical studies at a national level. To provide a benchmark for natural landscape management on a national scale, we use the travel cost method (TCM) and the contingent valuation method (CVM) to determine the economic value and the spatial distribution of natural landscapes across China. Our results show that the total economic value of China's natural landscape was $9.75 \times 10^{11}$ U.S. dollars (USD) in 2012. Of this value, the highest proportion was in the eastern and southwestern regions of China, which accounts for $23.7 \%$ and $18.3 \%$, respectively. The provinces of Guangdong, Sichuan, Yunnan, Inner Mongolia, and Heilongjiang were the top five in terms of the largest number of natural landscapes and largest economic values. Together, these five provinces accounted for $32.9 \%$ of the total number of natural landscapes and $29.4 \%$ of the total economic value in 2012 . We believe this study will increase awareness of the value of natural landscapes, and more importantly provide a scientific basis for resolving conflicts between development and resource conservation.
\end{abstract}

Keywords: travel cost method (TCM); contingent valuation method (CVM); natural landscape value; China

Citation: Xiao Yi, Cheng Cheng, Yang Wu, Ouyang Zhiyun, Rao Enming, 2016. Evaluating value of natural landscapes in China. Chinese Geographical Science, 26(2): 244-255. doi: 10.1007/s11769-015-0795-5

\section{Introduction}

Natural substances, environment, and phenomena make up natural landscapes, which provide many benefits to the human beings, including a sense of place, sightseeing, relaxing, and recuperating (Wang, 2011). With the development of social economies and improvements in people's living standards, many people have begun to enjoy natural scenery and outdoor recreation activities as part of a modern lifestyle. However, even though natural landscapes provide great social and economic benefits (Ma and Sun, 2001), their economic value was not recognized under the labor theory of value, which does not consider natural landscapes as embodying human labor and, thus, could not be traded in a real market (Hanley and Barbier, 2009). The consequence was a pervasive overexploitation and wasteful use of natural resources, causing an unprecedented magnitude of decline and degradation of ecosystems.

In the 1950s, environmental economists started to recognize that natural resources are not inexhaustible and that they have great economic value ( $\mathrm{Yu}$ et al., 2009). The escalating exploitation of natural resources and the aggravating of environmental problems forced scientific communities, government agencies, and nongovernment organizations to incorporate natural capital

Received date: 2015-03-30; accepted date: 2015-07-27

Foundation item: Under the auspices of National Science and Technology Support Program (No. 2011BAC09B08-02)

Corresponding author: CHENG Cheng. E-mail: chengchengdzy@163.com

(C) Science Press, Northeast Institute of Geography and Agroecology, CAS and Spri nger-Verlag Berlin Heidelberg 2016 
into the current socioeconomic accounting system (Brown and Nawas, 1973). By doing so, they hope to sustain the flow of ecosystem services and to maximize their benefits to improve human wellbeing (Ma and Sun, 2001; Lee and Han, 2002; Preez and Hosking, 2010).

The standard process of public project valuation was first proposed by Julse Dupuit in 1844, and the concept of 'consumer surplus' was used for the first time. Then, John Krutilla published 'Conservation Reconsidered' in 1967, which became the foundation for natural resource valuation (Freeman III, 2003; Ma, 2006). Natural resource valuation theories gradually matured and became more complete. In the 1970s and 1980s, the travel cost method (TCM) was widely used in the economic valuation of tourism resources, such as forest parks (Willis and Garrod, 1991). Then, in the 1980s, the contingent valuation method (CVM) became popular in studying people's willingness to pay for natural resources and nature-based activities (Caulkins et al., 1986). Subsequently, the hedonic priced method (HPM) was used to evaluate tourism value. More recently, in the 21 st century, many cases have combined the TCM and CVM to determine the value of natural resources (Blakemore and William, 2008; Loomis et al., 2008). These studies play an important role in natural resource management decisions and have had positive effects on people's sense of the environment.

In the 1980s, theories and methods of Western economics were introduced into China. Many Chinese researchers began to adopt the TCM, CVM, and HPM to evaluate the natural landscapes of China, such as forest parks (Chen and Chen, 1994; Xie and Ma, 2006), wetland parks, and tourism spots (Xue et al., 1999; Chen and Zhang, 2001; Yu et al., 2009). These studies introduced a new way for people and decision makers to realize the value of our natural environment, which played effective roles in landscape management. However, most research on natural landscape valuation focused on one or several landscapes. There have been very few large-scale empirical studies, whether in China or other countries. To provide a benchmark for natural landscape management on a national scale, we use non-market methods to evaluate the economic value and spatial distribution of natural landscapes across China. Our goal is to provide a foundation with which to study China's natural landscapes on a larger scale, as well as to provide decision makers with the information to make bet- ter and more informed decisions.

Natural landscape value has two parts: use value (UV) and non-use value (NUV) (Walsh et al., 1984; Daily, 1997). UV relates to the benefits directly derived from recreation, while NUV refers to value that has not been used previously, but can be used in the future, including option, existence, and bequest values (Greenley et al., 1981).

Several methods exist to estimate the value of recreational goods and services, including the TCM (Willis and Garrod, 1991; Garrod and Willis, 1999), the CVM (Bergstrom et al., 1990), the HPM (Bateman et al., 2002). Of these methods, the TCM remains the most common valuation technique used to measure the UV of a non-market resource. Therefore, it is the method we employ in this study. Then, we use the CVM to estimate the NUV of resources. We calculate the total value of a natural landscape as the sum of UV and NUV. Although we can represent the value of a natural landscape in currency form, we believe that this underestimates the real value of natural landscapes.

\section{Methods and Data}

\subsection{Travel cost method}

The TCM was first proposed in 1966 by the economist Clawson, and today is widely used as to assess non-market resources. It is suitable for valuating mature landscapes, but not suitable when a landscape has not yet been developed.

The TCM is a revealed preference approach, which considers the value that can be revealed by people's actions (Caulkins et al., 1986; Boxall et al., 1996). Therefore, the method is based on the following assumption: when people travel to visit a landscape, they may only need to pay a small amount of money for the ticket, but they still have to spend additional money for transportation, accommodation, shopping, and so on (Kim et al., 2010). These expenses are defined as travel costs (TC). In addition, they spend their time, which has value (time value, TV). In addition, the TCM creatively uses the concept of consumer surplus (CS) (Bateman et al., 1999; Bin et al., 2005), which is the difference between how much people actually pay and the highest amount they are willing to pay (Willis and Benson, 1989; He and Liu, 2008). As the travel expense increases for a particular natural landscape, the consumer surplus de- 
creases, as will the number of visitors. Eventually, the consumer surplus becomes zero and, theoretically, no one will visit the landscape if the cost continues to rise.

The use value (UV) of a natural landscape is the sum of consumer cost (CC) and the consumer surplus (CS) (Chen, 1996). The consumer cost includes the travel cost (TC) and the time value (TV) (Mendes, 2002). The time value is usually calculated as the money people could earn if they work instead of travel:

$$
\begin{aligned}
& U V=C C+C S \\
& C C=T C+T V \\
& T V=H \times W
\end{aligned}
$$

where $H$ is the time people spend at a landscape $(h)$ and $W$ is the visitor's wage rate (yuan (RMB)/h).

When we calculated the consumer surplus, we adopt the earliest developed model of travel cost method by Clawson and Knetch in 1966 (Clawson and Knetch, 1966), which is the zonal travel cost method. In this model, visitors are divided into different zones according to the distance between their origins and the landscape. The model assumes that the consumer costs are the same if people travel from the same zone ( $\mathrm{Li}$ and Pan, 2010; Li, 2010). Using a questionnaire survey, we obtained information about visitors' travel costs, time, income, education, and occupation for each zone.

For each zone, we introduced the variable visitation rate, which is the ratio of the number of visitors to the zone's population which comes from government website. Integrating all zone data, there is a functional relationship between consumer cost and visitation rate. A proportionate increase in consumer cost means the visitation rate and the number of visitors will decrease. The curve depicting the relationship between the consumer cost and the number of visitors is called the Clawson-Knetch curve $f(x)$ (Caulkins et al., 1986; Boxall et al., 1996). We kept increasing the consumer cost until no one visits the landscape. Then, the consumer surplus can be calculated as:

$$
C S=\int_{0}^{p_{\mathrm{m}}} f(x) \mathrm{d} x
$$

where $p_{\mathrm{m}}$ denotes the maximum consumer cost.

\subsection{Contingent valuation method}

The CVM is widely adopted in assessing environmental assets, and provides a suitable monetary valuation of non-priced services (Carson and Mitchell, 1993; Garrod and Willis, 1999). This method measures the value of recreational opportunities and amenities by gauging peoples' willingness to pay to use natural resources (Jim and Chen, 2006). The CVM has two underlying advantages. First, it is able to assess an individual's willingness to pay for hypothetical changes in the quality of recreational activities, as well as for present conditions (Liu, 2007). Second, the CVM is the only approach for determining the non-use value of environment amenities from the perspective of both users and non-users (Carson and Mitchell, 1993).

The key to using the CVM is reducing the bias from social surveys (Zhang et al., 2011). Four situations need to be considered by researchers. The first is that the description of the situation is different from the real fact, so the feedback from the respondent is not as significant as planned. The second is the starting point of the payment, which should be set up with caution, because the starting point can affect people's pay behavior psychologically. Then, if people know that their response may affect their own life, they tend to respond in such a way as to enhance their benefits. The fourth situation is that people do not think their response will be useful in a decision-making process. This is particularly relevant in China. In this case, they may attach importance to the survey and, thus, do not want to be responsible for their answers.

In this study, we considered all four of the aforementioned situations. First, we trained each inquirer in how to describe the situation to make sure that respondents fully understood our purposes and to ensure they understood that their feedback had value. Second, we set the payment based on an exhaustive review of other research in China. As a result, we were able to largely avoid the pitfalls of the fours situations and our use of the CVM and our results are robust.

Direct inquiry (such as face-to-face and telephone interviews and e-mail) is usually used to establish people's willingness to pay for the protection of a site. Here, we use the median value of people's willingness to pay as the payment (Zhang, 2007). In other words, we use the amount people are willing to pay when the cumulative payment frequency reaches $50 \%$. Then, we identified the population of affected people (Garrod and Willis, 1999; Bateman et al., 2002), and obtained the NUV through the following formula: 


$$
N U V=M \times R \times P
$$

where $M$ is the payment, $R$ is the pay rate (i.e., the percentage of people who have the willingness to pay), and $P$ is the number of people who have the potential to pay.

\subsection{Questionnaire design}

In the TCM and the CVM, we need to know visitors' socioeconomic characteristics, travel expenses and time costs, and their willingness to pay. Although this information can be acquired by telephone or e-mail, we chose to use a face-to-face questionnaire survey to ensure visitors understand our purpose and to finish the questionnaire effectively. The questionnaire includes three parts (Table 1): a visitor's socioeconomic characteristics, travel information, and willingness to pay to protect the natural environment of the landscape.

\subsection{Data of sample landscapes}

This study collected a list of natural landscapes from the official website of the National Tourism Administration (2011-2012), the State Forestry Bureau (2011-2012), and the Ministry of Land and Resources (2011-2012). As the investigation in Hong Kong, Macao and Taiwan regions can be very costly in both time and fund, and we are lake of the basic population information of those regions, so our survey does not contain natural landscapes in Hong Kong, Macao and Taiwan regions. In all, there are 4477 natural landscapes grouped into five categories according to the main attraction of each natural landscape: scenic spots, nature reserves, geo- logical parks, forest parks, and wetland parks. To facilitate our research, we also classify the landscapes into four classes: world, national, regional, and local according to their ecological significance and rareness to mankind. Then, each natural landscape is tagged according to its category and class (Table 2).

As the number of natural landscapes is too large to investigate individually, we select representative samples according to geographical location, categories, and classes. In order to pick representative samples, we consider the samples' class and landscape type carefully. Lastly, we choose 29 natural landscapes in which to conduct the questionnaire survey (Fig. 1). The 29 landscapes cover all categories and classes and are distributed across 12 provinces, which account for more than one-third of the provinces of China. In addition, the selected landscapes are distributed evenly across the four classes.

In the later calculation, we find that category has a minimum effect on the value per unit area $(P=0.316)$ in an Analysis of Variance (ANOVA) analysis, so we only use class to identify landscape values. As funding and time are limited, the number of landscapes we investigated on site is also limited. Therefore, we do not study the enough landscapes for each category and class. Instead, we use an average value for each class. Different values are assigned to the 4477 natural landscapes according to their classes, giving us the spatial distribution of the natural landscape value in China.

As our research is conducted in both 2011 and 2012, the value can be affected by currency inflation between the two years. Researchers typically choose $3 \%-7 \%$ as a

Table 1 Summary of questionnaire survey

\begin{tabular}{ll}
\hline \multicolumn{1}{c}{ Part } & Content \\
\hline $\begin{array}{l}\text { Socioeconomic characteristics } \\
\text { Travel information }\end{array}$ & $\begin{array}{l}\text { Expenses and time cost; expenses including transportation, accommodation, food, tickets for entrance or shows, } \\
\text { shopping; time cost including the value of time spent in the landscape and also time on the road }\end{array}$ \\
$\begin{array}{l}\text { Willingness to pay to protect natural } \\
\text { environment of this landscape }\end{array}$ & \begin{tabular}{l} 
If a visitor is willing to pay, then this provides the amount in a year; if not, then the visitor is asked to provide reasons \\
\hline
\end{tabular}
\end{tabular}

Table 2 Distribution of natural landscapes in different categories and classes

\begin{tabular}{|c|c|c|c|c|c|c|}
\hline Classes & Scenic spot & Nature reserve & Geological park & Forest park & Wetland park & Total \\
\hline World class & 23 & 7 & 1 & 0 & 1 & 32 \\
\hline National class & 57 & 30 & 14 & 25 & 0 & 126 \\
\hline Regional class & 449 & 263 & 114 & 0 & 0 & 826 \\
\hline Local class & 857 & 2097 & 0 & 505 & 34 & 3493 \\
\hline Total & 1386 & 2397 & 129 & 530 & 35 & 4477 \\
\hline
\end{tabular}




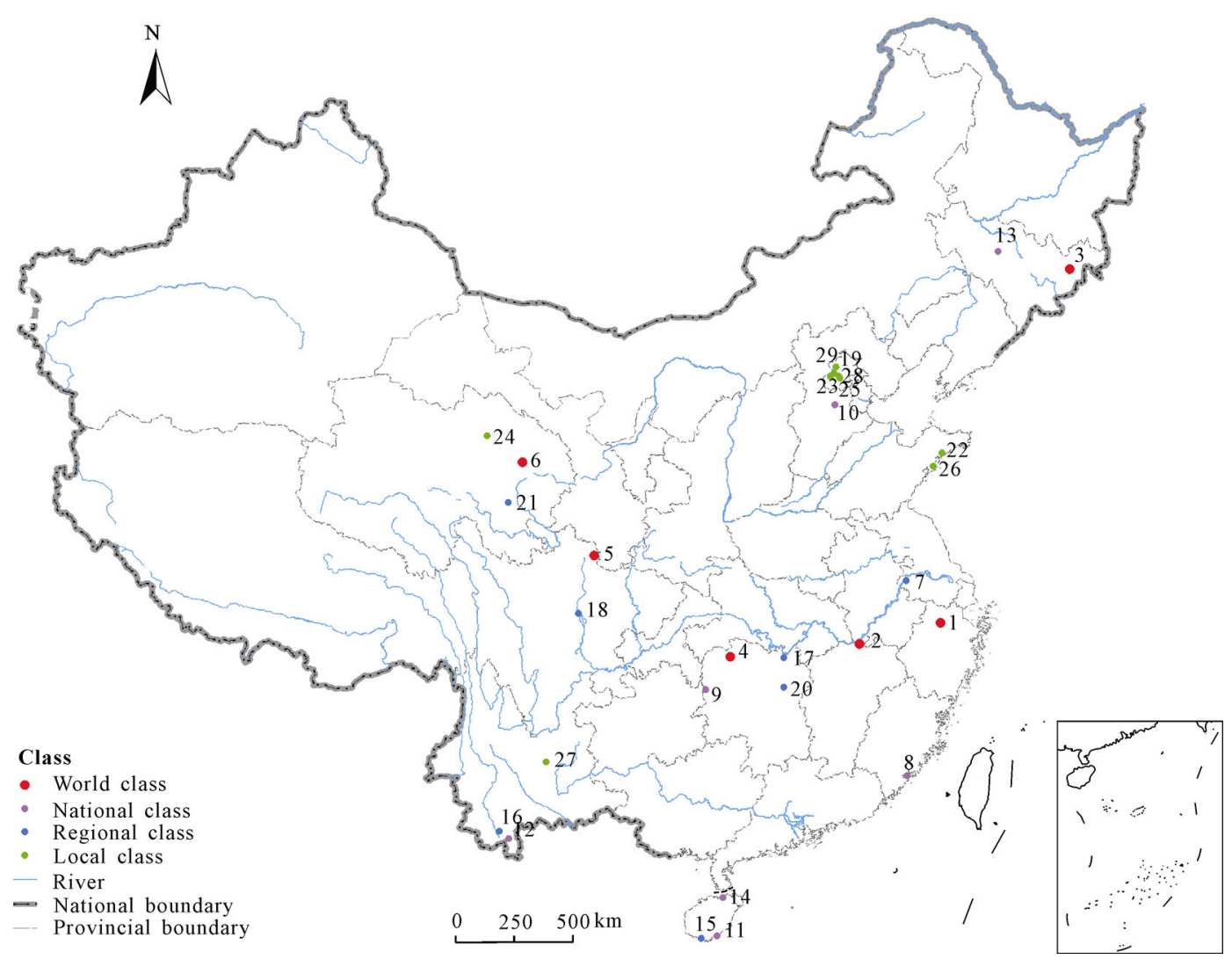

Fig. 1 Natural landscape sample locations. There are detail information of each landscape in Table 3

discount rate. Thus, we adopt a discount rate of $5 \%$ (Yang et al., 2008) to eliminate the effect of currency inflation, and convert the 2011 values into 2012 values (Table 3).

\section{Results}

\subsection{Natural landscape samples}

After analyzing the data from the questionnaire survey, we calculate the use value and non-use value of each natural landscape using the methods described in Section 2. The details and values are shown in Table 3.

\subsection{Natural landscape value in China}

We use the average value of the samples to represent the value of landscapes in the same class. The average value for each world, national, regional, and local class natural landscape is $2392.59 \times 10^{6}, 802.30 \times 10^{6}, 429.82 \times 10^{6}$, and $125.86 \times 10^{6} \mathrm{U}$. s. dollar (USD), respectively.

\subsubsection{Overall value distribution in China}

In 2012, the total economic value of natural landscapes in China (not including Hong Kong, Macao and Taiwan regions) was $9.75 \times 10^{11}$ USD (Fig. 2). Figure 3 shows the relationship between natural landscape value and land area, with almost all natural landscape value distributed within $70 \%$ of the national territorial area.

Study area is divided into four regions according to landscape value distributions: the vital region, the important region, the medium region, and the common region (Table 4). The vital region covers $6.9 \%$ of China, comprising the southeastern coastal areas and some central and western regions. The important and medium regions account for $10.35 \%$ and $15.90 \%$, respectively, and are widely distributed in the central and eastern China. The common region accounts for $66.85 \%$, mainly in the western and northern China.

\subsubsection{Value analysis based on geographical area}

There are seven geographic regions in China: the eastern, southern, northern, central, southwestern, northwestern, and northeastern regions. The value of each region is shown in Table 5. East China's value is the highest, and has the biggest vital area among the seven regions. 
Table 3 Information and values for natural landscapes which were selected for survey by face-to-face inquiry

\begin{tabular}{|c|c|c|c|c|c|c|c|c|c|c|}
\hline $\begin{array}{c}\text { Class } \\
\text { (number) }\end{array}$ & Order & Landscape name & $\begin{array}{c}\text { Province } \\
\text { (municipality) }\end{array}$ & $\begin{array}{l}\text { Number of } \\
\text { visitors } \\
\left(10^{3}\right)\end{array}$ & $\begin{array}{l}\text { Payment } \\
\text { (USD) }\end{array}$ & $\begin{array}{c}\text { Pay rate } \\
(\%)\end{array}$ & $\begin{array}{l}\text { Survey } \\
\text { year }\end{array}$ & $\begin{array}{l}\text { Use value } \\
\text { in } 2012 \\
\left(10^{6} \mathrm{USD}\right)\end{array}$ & $\begin{array}{c}\text { Non-use } \\
\text { value in } 2012 \\
\left(10^{6} \mathrm{USD}\right)\end{array}$ & $\begin{array}{c}\text { Value in } \\
2012 \\
\left(10^{6} \mathrm{USD}\right)\end{array}$ \\
\hline \multirow{6}{*}{$\begin{array}{l}\text { World } \\
(6)\end{array}$} & 1 & West Lake & Zhejiang & 30000 & 8.07 & 71.79 & 2011 & 7193.28 & 274.63 & 7468.04 \\
\hline & 2 & Lushan National Park & Jiangxi & 6475 & 6.94 & 66.16 & 2012 & 1858.65 & 109.88 & 2066.89 \\
\hline & 3 & Changbai Mountains & Jilin & 1400 & 11.67 & 77.30 & 2012 & 1480.56 & 136.57 & 1617.13 \\
\hline & 4 & Wulingyuan Scenic Area & Hunan & 5043.7 & 10.14 & 65.73 & 2011 & 1288.89 & 224.53 & 1513.34 \\
\hline & 5 & Jiuzhaigou Valley Scenic Area & Sichuan & 2860 & 6.82 & 59.78 & 2012 & 1157.33 & 137.40 & 1293.74 \\
\hline & 6 & Qinghai Lake & Qinghai & 850 & 8.73 & 75.76 & 2012 & 330.31 & 66.39 & 396.71 \\
\hline \multirow{8}{*}{$\begin{array}{l}\text { National } \\
\text { (8) }\end{array}$} & 7 & Fuzimiao-Qinhuaihe Scenic Spot & Jiangsu & 9159 & 5.97 & 64.32 & 2011 & 1489.20 & 187.51 & 1676.61 \\
\hline & 8 & Gulangsu & Fujian & 6500 & 7.88 & 68.72 & 2012 & 1071.50 & 130.81 & 1202.31 \\
\hline & 9 & Fenghuanggucheng Scenic Spot & Hunan & 5200 & 7.21 & 65.22 & 2011 & 995.34 & 154.47 & 1149.75 \\
\hline & 10 & Baiyang Lake & Hebei & 1350 & 9.88 & 63.08 & 2012 & 145.63 & 192.26 & 337.89 \\
\hline & 11 & Nanwanmihou Nature Reserve & Hainan & 900 & 4.94 & 65.63 & 2012 & 235.26 & 16.47 & 251.73 \\
\hline & 12 & $\begin{array}{l}\text { Xishuangbanna Tropical } \\
\text { Botanical Garden Chinese } \\
\text { Academy of Science }\end{array}$ & Yunnan & 600 & 7.90 & 70.41 & 2012 & 107.91 & 88.14 & 196.05 \\
\hline & 13 & Jingyuetan National Forest Park & Jilin & 1095 & 7.98 & 75.9 & 2012 & 55.52 & 89.46 & 144.98 \\
\hline & 14 & $\begin{array}{l}\text { Leiqiong National Geological } \\
\text { Park }\end{array}$ & Hainan & 420 & 8.04 & 52.91 & 2012 & 51.07 & 19.44 & 70.51 \\
\hline \multirow[t]{7}{*}{$\begin{array}{l}\text { Regional } \\
\text { (7) }\end{array}$} & 15 & $\begin{array}{l}\text { Tianyahaijiao Coastal Scenic } \\
\text { Spot }\end{array}$ & Hainan & 3540 & 7.22 & 53.70 & 2012 & 557.33 & 29.49 & 586.82 \\
\hline & 16 & Yexianggu Wild Elephant Valley & Yunnan & 1033.9 & 7.08 & 65.85 & 2012 & 496.05 & 75.45 & 571.50 \\
\hline & 17 & Dongting Lake & Hunan & 500 & 5.15 & 71.96 & 2012 & 40.86 & 344.15 & 385.01 \\
\hline & 18 & Qingcheng Mountain & Sichuan & 1600 & 9.43 & 60.41 & 2012 & 198.19 & 185.67 & 383.86 \\
\hline & 19 & Fragrence Hill & Beijing & 4998 & 7.33 & 50.51 & 2012 & 317.13 & 57.00 & 374.14 \\
\hline & 20 & Yuelu Mountain & Hunan & 1000 & 7.98 & 67.88 & 2011 & 116.42 & 160.87 & 277.76 \\
\hline & 21 & Kanbula Geological Park & Qinghai & 100 & 5.73 & 52.37 & 2012 & 29.16 & 68.86 & 98.52 \\
\hline \multirow{8}{*}{$\begin{array}{l}\text { Local } \\
(8)\end{array}$} & 22 & Qingdao Xinhao Mountain & Shandong & 400 & 9.46 & 56.00 & 2012 & 29.98 & 243.66 & 273.64 \\
\hline & 23 & Yuyuantan Park & Beijing & 6000 & 3.81 & 36.27 & 2012 & 176.28 & 20.76 & 197.03 \\
\hline & 24 & Beishan Forest Park & Qinghai & 360 & 4.25 & 76.83 & 2012 & 138.55 & 8.57 & 147.12 \\
\hline & 25 & Zizhuyuan Bamboo Park & Beijing & 7500 & 1.57 & 66.67 & 2011 & 121.09 & 22.14 & 143.16 \\
\hline & 26 & Qingdao Botanic Garden & Shandong & 250 & 4.70 & 49.19 & 2012 & 5.93 & 105.44 & 111.37 \\
\hline & 27 & Jindian Forest Park & Yunnan & 800 & 6.47 & 68.21 & 2012 & 29.16 & 68.86 & 98.02 \\
\hline & 28 & Baiwangshan Forest Park & Beijing & 800 & 2.70 & 76.88 & 2011 & 15.74 & 42.90 & 58.48 \\
\hline & 29 & Mangshan Forest Park & Beijing & 150 & 3.35 & 51.79 & 2012 & 3.94 & 0.26 & 4.28 \\
\hline
\end{tabular}

Note: 1 USD = 6.07 yuan (RMB) in Dec. 2012

3.2.3 Value analysis based on administrative division As shown in Table 6, the Guangdong Province has the most natural landscapes (429), followed by Heilongjiang (290), and Inner Mongolia (265). The Sichuan, Yunnan, and Jiangxi provinces all have more than 200 natural landscapes. In contrast, the Qinghai, Ningxia,
Tianjin, and Shanghai provinces have far fewer natural landscapes (less than 30). In 2012, the Guangdong Province had the largest natural landscape value $(7.21 \times$ $10^{10}$ USD), followed by the Sichuan Province $(6.22 \times$ $\left.10^{10} \mathrm{USD}\right)$, and the Yunnan Province (5.27 $\left.\times 10^{10} \mathrm{USD}\right)$. Together, these three provinces account for $19.17 \%$ of 


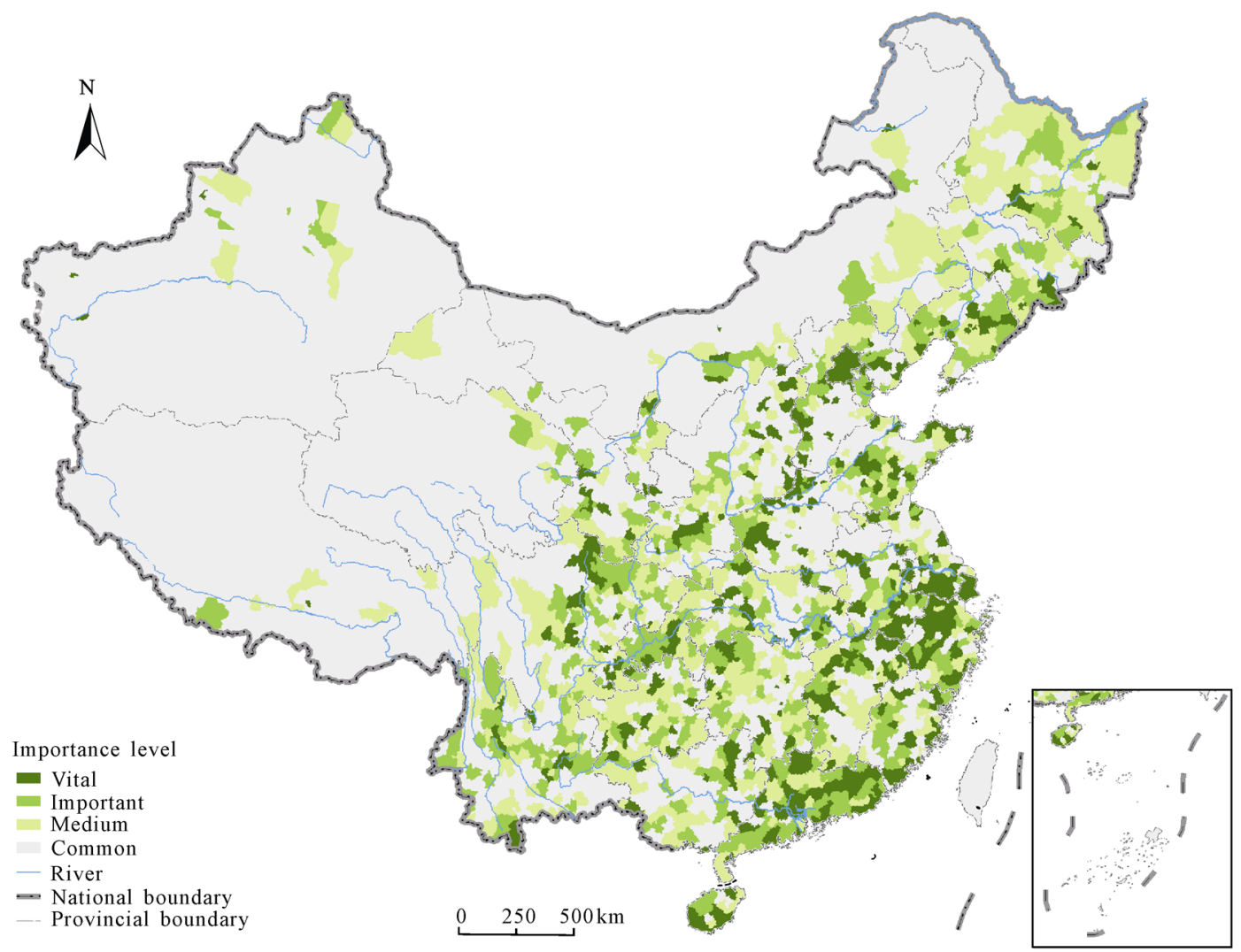

Fig. 2 Natural landscape value distributions at county scale in China. Description of level is in Table 4

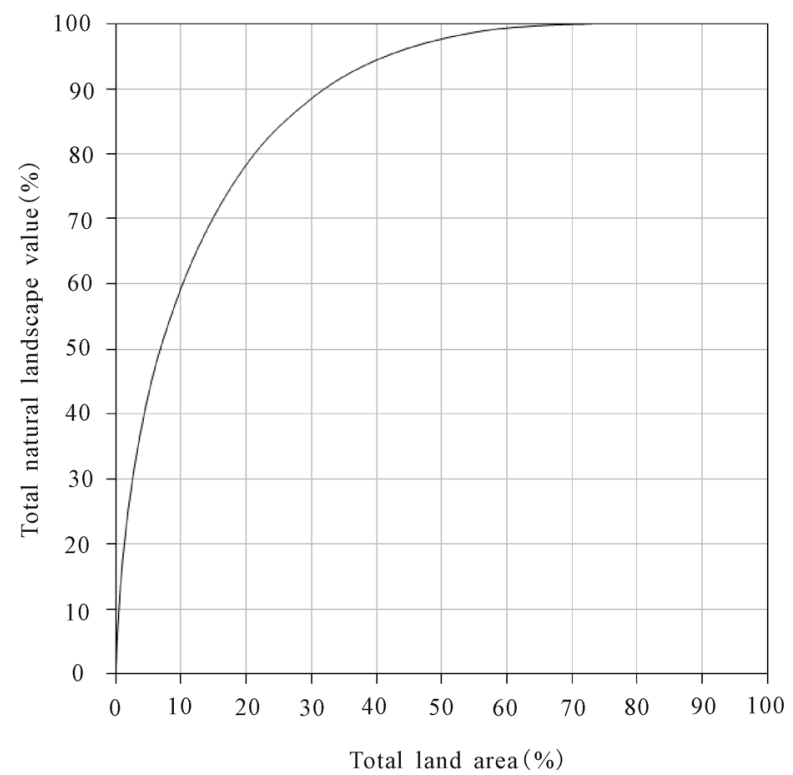

Fig. 3 Natural landscape value distributions

the total landscape value in China.

Analyzing the top three provinces in natural landscape value, we discover that Guangdong has the largest value because it has the most local class natural landscapes, almost twice the number in Sichuan. However,
Table 4 Natural landscape value distributions in China

\begin{tabular}{llcc}
\hline Region & $\begin{array}{c}\text { Landscape value }\left(10^{3}\right. \\
\left.\text { USD } / \mathrm{km}^{2}\right)\end{array}$ & $\begin{array}{c}\text { Area } \\
\left(10^{4} \mathrm{~km}^{2}\right)\end{array}$ & $\begin{array}{c}\text { Percent } \\
(\%)\end{array}$ \\
\hline Vital & $>329.49$ & 65.26 & 6.90 \\
Important & $164.74-329.49$ & 97.89 & 10.35 \\
Medium & $65.90-164.74$ & 150.38 & 15.90 \\
Common & $<65.90$ & 632.27 & 66.85 \\
\hline
\end{tabular}

Note: not including Hong Kong, Mocao and Taiwan regions

Sichuan has the most world-class natural landscapes, including some of the most famous of China's tourist sites, such as Jiuzhaigou, Huanglong, and Emei Mountains. Lastly, Yunnan has an impressive number of landscapes in each of the world, national, and regional classes.

\section{Discussion}

\subsection{Robustness of methods and results}

We use the TCM and CVM to evaluate 4477 natural landscapes in China, in which 29 landscape are valuated directly, and others' value are assigned. We then calculate the value for the natural landscapes in each class. 
Table 5 Natural landscape value of seven geographic regions

\begin{tabular}{|c|c|c|c|c|c|c|}
\hline \multirow{2}{*}{ Region } & \multicolumn{2}{|c|}{ Natural landscape value } & \multicolumn{4}{|c|}{ Area $\left(10^{4} \mathrm{~km}^{2}\right)$} \\
\hline & Value ( $\left.10^{9} \mathrm{USD}\right)$ & Percent (\%) & Vital & Important & Medium & Commom \\
\hline Eastern China & 230.44 & 23.68 & 22.76 & 13.85 & 16.34 & 27.03 \\
\hline Southwestern China & 178.48 & 18.34 & 9.50 & 25.05 & 37.48 & 160.98 \\
\hline Northwestern China & 139.52 & 14.34 & 4.78 & 17.31 & 41.70 & 60.54 \\
\hline Southern China & 125.12 & 12.86 & 10.89 & 10.73 & 10.83 & 12.47 \\
\hline Central China & 102.34 & 10.52 & 7.63 & 10.95 & 14.50 & 23.25 \\
\hline Northwestern China & 99.22 & 10.20 & 3.00 & 12.59 & 21.78 & 294.38 \\
\hline Northern China & 97.90 & 10.06 & 6.88 & 7.27 & 7.83 & 53.87 \\
\hline
\end{tabular}

Table 6 Natural landscape value of each province (autonomous region, municipality)

\begin{tabular}{|c|c|c|c|c|c|}
\hline \multirow{2}{*}{$\begin{array}{c}\text { Province } \\
\text { (municipality) }\end{array}$} & \multirow{2}{*}{ Natural landscape number } & \multirow{2}{*}{ Area $\left(10^{4} \mathrm{~km}^{2}\right)$} & \multirow{2}{*}{ Percent $(\%)$} & \multicolumn{2}{|c|}{ Natural landscape value } \\
\hline & & & & Value ( $\left(10^{9} \mathrm{USD}\right)$ & Percent (\%) \\
\hline Guangdong & 429 & 17.73 & 1.87 & 72.11 & 7.39 \\
\hline Sichuan & 249 & 48.38 & 5.11 & 62.21 & 6.38 \\
\hline Yunnan & 241 & 38.32 & 4.05 & 52.67 & 5.40 \\
\hline Inner Mongolia & 265 & 114.70 & 12.12 & 50.15 & 5.14 \\
\hline Heilongjiang & 290 & 45.28 & 4.78 & 49.91 & 5.12 \\
\hline Jiangxi & 232 & 16.70 & 1.76 & 43.57 & 4.47 \\
\hline Zhejiang & 172 & 10.19 & 1.08 & 42.50 & 4.36 \\
\hline Hunan & 168 & 21.20 & 2.24 & 39.94 & 4.09 \\
\hline Liaoning & 183 & 14.56 & 1.54 & 39.11 & 4.01 \\
\hline Anhui & 186 & 14.03 & 1.48 & 38.18 & 3.91 \\
\hline Shandong & 183 & 15.42 & 1.63 & 37.73 & 3.87 \\
\hline Guangxi & 134 & 23.62 & 2.49 & 34.09 & 3.50 \\
\hline Hubei & 151 & 18.60 & 1.96 & 33.47 & 3.43 \\
\hline Jiangsu & 130 & 10.09 & 1.07 & 33.26 & 3.41 \\
\hline Hebei & 109 & 18.73 & 1.98 & 31.97 & 3.28 \\
\hline Fujian & 139 & 12.17 & 1.29 & 31.21 & 3.20 \\
\hline Henan & 119 & 16.55 & 1.75 & 30.52 & 3.13 \\
\hline Guizhou & 168 & 17.60 & 1.86 & 28.95 & 2.97 \\
\hline Gansu & 116 & 40.53 & 4.28 & 27.64 & 2.83 \\
\hline Beijing & 104 & 1.64 & 0.17 & 27.02 & 2.77 \\
\hline Xinjiang & 107 & 163.19 & 17.24 & 23.74 & 2.43 \\
\hline Shanxi & 111 & 20.59 & 2.17 & 23.74 & 2.43 \\
\hline Jilin & 102 & 19.09 & 2.02 & 21.32 & 2.19 \\
\hline Shanxi & 86 & 15.65 & 1.65 & 20.59 & 2.11 \\
\hline Chongqing & 99 & 8.24 & 0.87 & 20.03 & 2.05 \\
\hline Hainan & 66 & 5.03 & 0.53 & 17.60 & 1.80 \\
\hline Xizang & 55 & 120.30 & 12.71 & 14.49 & 1.49 \\
\hline Qinghai & 27 & 71.57 & 7.56 & 9.38 & 0.96 \\
\hline Ningxia & 23 & 5.19 & 0.55 & 7.12 & 0.73 \\
\hline Shanghai & 14 & 0.62 & 0.07 & 5.55 & 0.57 \\
\hline Tianjin & 19 & 1.16 & 0.12 & 5.50 & 0.56 \\
\hline
\end{tabular}


According to the number and distribution of natural landscapes, we determine the total value and the spatial distribution for each class. Thus, it is necessary to establish the validity of the evaluation process and the authenticity of the data resources. The natural landscape list comes from official websites of the National Tourism Administration, the State Forestry Bureau, and the Ministry of Land and Resources. This ensures the correctness of the original data about basic landscape information.

In order to make sure the data are solid, we sent four well-trained investigators to complete the 200 questionnaires (this number is similar to most other studies in China) in two or three days for each landscape. The validity rate for the questionnaire for each landscape is above $90 \%$. Thus, for both the TCM and the CVM, we try to ensure that our original data are efficient and effective, and to avoid the bias caused by one investigator or one particular day.

When using the TCM, we handle group tours and multi-destination tours carefully, because it is difficult to determine the travel cost attributed to the landscape in question from the destinations people travel to (always more than one). Some researchers ask visitors to rate landscapes based on their objective feelings. However, feelings are not in direct proportion to the actual cost. We believe the time that visitors spend in a landscape reflects the expense on a landscape, as more time produces more costs in terms of accommodation and shopping, as well as an increase in time value. Therefore, we allocate a travel cost that covers all destinations according to the time visitors spend at a destination.

In the CVM, we try to reduce as much bias as possible. To this end, we train each inquirer to describe the situation in order to make sure respondents fully understand our purpose, and to make them feel that their feedback has value. We set the payment based on an exhaustive review of other research in China, ensuring that the inquirers do not affect visitors' responses. Thus, our use of the CVM and our results are robust.

There are 4477 natural landscapes in our study, from which we select 29 representative samples. Naturally, the number of samples number is too small to cover the whole country. As a result of funding and time limitations, we can not investigate more samples. However, the 29 samples are chosen in a systematic way: we divide China (not including Hong Kong, Macao and Taiwan regions) into seven regions (the eastern, southern, northern, central, southwestern, northwestern, and northeastern regions) according to geographic and economic criteria. Although some provinces are not covered in our survey, the 29 samples are evenly distributed across the four regions. In this way, we simplify the investigation and ensure our survey is scientifically based.

\subsection{Influence on landscape value of number of visitors, area of landscape, payment, and pay rate}

Since natural landscape value is affected by many factors, such as the number of visitors, the visitor structure, and urban population, it is inevitable that for some landscapes, the calculated values differ from the actual situation. For example, West Lake and Changbai Mountains are both world-class landscapes, but West Lake's value is four times greater than that of Changbai Mountains, which is even a bit less than that of FuzimiaoQinhuaihe Scenic Spot, a national class landscape. The direct reason for the value is related to the number of visitors: West Lake has $3.0 \times 10^{7}$ visitors annually, and Fuzimiao-Qinhuaihe Scenic Spot has $9.1 \times 10^{6}$ visitors. However, Changbai Mountains has only $1.4 \times 10^{6}$ annually. The use values and non-use values are both affected by the number of visitors. As the class is defined according to landscape's ecological significance and rareness to mankind, but the calculated value can be largely influenced by visitor number, so for some landscapes, the calculated value may not reflect the real value a landscape stands for, and this is the systematic error of the study. On the other hand, the area of the landscape affects the number of visitors directly. Using the same example, West Lake and Fuzimiao-Qinhuaihe Scenic Spot are both located in the eastern China, which have well-developed economies and convenient transportation. However, Changbai Mountains is located in the northeastern China where the economy is not as well developed. In addition, Changbai Mountains is relatively far away from the central city, which means transportation is not as convenient. In conclusion, in our model, the value of a landscape can be affected by the number of visitors and the location of the landscape. For example, the world-class landscape Changbai Mountains, the value of which is underestimated, has a lower value. However, this does not mean that the actual value of the Changbai Mountains landscape is lower than that of FuzimiaoQinhuaihe Scenic Spot. Instead, the imperfect method contains bias, and the economic valuation is not absolute 
objective but can be affected by people's behavior.

In the CVM, when analyzing the payment and pay rate of the 29 natural landscape samples, we find, in general, that a higher class has a higher payment and a higher pay rate. However, the distinction is not necessarily obvious, because the payments are concentrated between 40 and 60 yuan (RMB)/yr, and the pay rate is concentrated between $50 \%$ and $70 \%$ for most natural landscapes. For example, visitors at the famous Lushan Mountain or those at the small park in Qingdao (Xinhaoshan Park) always chose 40 or 50 yuan (RMB)/yr. This phenomenon makes it difficult for us to distinguish landscapes that have different values from an economic perspective. Although most visitors are positive when asked about their willingness to pay for the protection of a natural landscape, they seem not to seriously consider the significance or meaning of the landscape when providing a payment. Instead, they are inclined to choose an innocuous amount to 'donate' to environmental protection. Getting people to fully realize the value of natural landscapes and enhancing their sense of protecting nature still have a long way to go in China.

Natural resources can not be traded in a real market, making their valuation difficult. Different researchers, seasons, and environmental conditions cause a natural landscape value to change, which means we need to analyze the value under specific conditions. However, in a society with rapid economic development, we need tools and foundations to solve problems when developing natural resources. The TCM and CVM are imperfect, but they are the most widely used methods when it comes to evaluating natural resources. In this study, we add the value calculated using the TCM to the value calculated using the CVM to represent the landscape value, although this may cause bias, because the two methods use different valuation systems. However, the value underestimates the real value, which is adequate as a reference or a low value of China's natural landscape value for future researchers until better techniques emerge. In addition, since 4477 landscapes were evaluated as a united system and we obtain a value distribution for China, we believe the results will prove useful to decision makers in future.

\subsection{Implications for conservation and manage- ment}

We can ensure the correctness of our data to some ex- tent, but there are some natural landscapes already in uses that have not been declared as scenic spots or nature reserves. In addition, other landscapes have not been used as yet, so we omit these from our research. Therefore, from this perspective, the calculated value is much less than the real value of the natural landscapes.

Many natural landscapes in our samples are worldfamous tourist spots, and tens of thousands of foreign visitors visit them every year. The travel costs for these visitors are much greater than those of the average Chinese visitors. However, because of the lack of basic statistical data on population and income, we can not include foreign visitors in our evaluation. Therefore, this is another reason why the calculated value is less than the true value of nature. Note that natural landscapes are precious resources for everyone, and the destruction of natural landscapes is not only a loss to one country, but to the world.

Now that we have a reference for each landscape's value in a particular class and the method we use to reveal this value, we provide a simple guide for people who want to know about the value of a natural landscape in order to make better decisions. In addition, we reveal the spatial distribution of the natural landscape values, and discover important regions in which landscapes are concentrated. Thus, in the case of construction programs that may impact the natural environment or increase the number of visitors beyond an upper limit, decision makers could use our data to calculate the economic tradeoff between gains and losses.

\section{Conclusions}

The value of a natural landscape has great significance to society, and they provide various benefits to people. This study adopts the TCM and VCM to evaluate natural landscape's use value and non-use value. After evaluating four classes of landscapes, we reveal the total natural landscape value of China and the value distribution from a spatial perspective. The main conclusions are as follows.

(1) In 2012, the natural world-class landscape value was $2.39 \times 10^{9} \mathrm{USD}$, that of the national class was $8.02 \times 10^{8} \mathrm{USD}$, the regional class was $4.30 \times 10^{8} \mathrm{USD}$, and the local class was $1.25 \times 10^{8}$ USD.

(2) In 2012, the value of the natural landscape of China was $9.75 \times 10^{11}$ USD. According to the natural 
landscape value per kilometer, we identify four regions with different value significance. Vital regions occupy $6.9 \%$ of China (not including Hong Kong, Macao and Taiwan regions), mainly in the country's southeastern coastal areas and some central and western regions. Then important and medium regions account for $10.35 \%$ and $15.90 \%$, respectively, and are widely distributed in the central and eastern China. Lastly, the region accounts for $66.85 \%$, mainly in the western and north China.

(3) When analyzing natural the landscape value from an administrative division perspective, we find that Guangdong has the highest value $\left(7.21 \times 10^{10} \mathrm{USD}\right)$, followed by Sichuan $\left(6.22 \times 10^{10}\right.$ USD), and Yunnan $\left(5.23 \times 10^{10} \mathrm{USD}\right)$.

(4) From the perspective of the seven geographic areas in China, the eastern China has the highest natural landscape value $(23.68 \%)$, as well as the largest area of vital value regions. The southwestern China contributes $18.34 \%$ of the total natural landscape value. The northern, northwestern, and central China have relatively little natural landscape value, accounting for about only $10 \%$ of the total value of China.

\section{References}

Bateman I J, Brainard J S, Lovett A A et al., 1999. The impact of measurement assumptions upon individual travel cost estimates of consumer surplus: a GIS analysis. Regional Environmental Change, 1(1): 24-30. doi: 10.1007/s10113 0050005

Bateman I J, Carson R T, Day B et al., 2002. Economic Valuation with Stated Preference Techniques: A Manual. Cheltenham: Edward Elgar Publishing Ltd.

Bergstrom J C, Stoll J R, Titre J P et al., 1990. Economic value of wetlands-based recreation. Ecological Economics, 2(2): 129147. doi: 10.1016/0921-8009(90)90004-E

Bin O, Landry C E, Ellis C L et al., 2005. Some consumer surplus estimates for North Carolina beaches. Marine Resource Economics, 20(2): 145-161.

Blakemore F, Williams A, 2008. British tourists' valuation of a Turkish Beach using contingent valuation and travel cost methods. Journal of Coastal Research, 246: 1469-1480. doi: 10.2112/06-0813.1

Boxall P C, Adamowicz W L, Swait J et al., 1996. A comparison of stated preference methods for environmental valuation. Ecological Economics, 18(3): 243-253. doi: 10.1016/09218009(96)00039-0

Brown W G, Nawas F, 1973. Impact of aggregation on the estimation of outdoor recreation demand functions. American Journal of Agricultural Economics, 55(2): 246-249. doi:

\section{$10.2307 / 1238448$}

Carson R T, Mitchell R C, 1993. The value of clean water: the public's willingness to pay for boatable, fishable, and swimmable quality water. Water Resources Research, 29: 2445-2454. doi: 10.1029/93WR00495

Caulkins P P, Bishop R C, Bouwes N W, 1986. The travel cost model for lake recreation: a comparison of two methods for incorporating site quality and substitution effects. American Journal of Agricultural Economics, 68(2): 291-297. doi: 10. $2307 / 1241430$

Chen Fu, Zhang Jie, 2001. Analysis on capialization accounting of travel value - a case study of Jiuzhaigou scenic spot. Journal of Nanjing University, 37(3): 296-303. (in Chinese)

Chen Yingfa, Chen Fangming, 1994. Two popular methods for forest tourism valuation abroad. Journal of Beijing Forest University, 16(3): 97-105. (in Chinese)

Chen Yingfa, 1996. Cost method: a practical valuation method to evaluate forest recreational value. Ecological Economy, (3): 27-31. (in Chinese)

Clawson M, Kentsch J L, 1966. Economics of Outdoor Recreation. Maryland: The Johns Hopkins Press.

Daily G C, 1997. Nature's Services: Societal Dependence on Natural Ecosystems. Washington: Island Press.

Freeman III A M, 2003. The Measurements of Environmental and Resource Values: Theory and Methods. Washington: RFF Press.

Garrod G, Willis K G, 1999. Economic Valuation of the Environment: Methods and Case Studies. Cheltenham: Edward Elgar Pub, England.

Greenley D A, Walsh R G, Young R A, 1981. Option value: empirical evidence from a case study of recreation and water quality. The Quarterly Journal of Economics, 96(4): 657-673. doi: $10.2307 / 1880746$

Hanley N, Barbier E, 2009. Pricing Nature: Cost-benefit Analysis and Environmental Policy. Cheltenham: Edward Elgar Pub.

He Shuping, Liu Jing, 2008. The consumer surplus in western economics. Journal of Harbin University of Commerce, 99(2): 111-114. (in Chinese)

Jim C, Chen W Y, 2006. Recreation-amenity use and contingent valuation of urban greenspaces in Guangzhou, China. Landscape and Urban Planning, 75: 81-96. doi: 10.1016/j. landurbplan.2004.08.008

Kim S G, Bowker J M, Cho S H et al., 2010. Estimating travel cost model: spatial approach. Agricultural and Applied Economics Association, 1-17.

Lee C K, Han S Y, 2002. Estimating the use and preservation values of national parks tourism resources using a contingent valuation method. Tourism Management, 23: 531-540. doi: 10.1016/S0261-5177(02)00010-9

Li Na, Pan Wen, 2010. Using travel cost interval analysis to evaluate the recreational benefits of Shennongjia Nature Reserve. Ecological Economy, (1): 35-41. (in Chinese)

Li Xueyan, 2010. Evaluation of recreation value of Canus scenes' tourism resources. Forest Resources Management, 4: 88-92. (in Chinese) 
Liu Xianghua, 2007. The theoretic improvement and its application of CVM in the valuation if Qixinghe wetland services. Ecological Environment, (2): 317-320. (in Chinese)

Loomis J, Tadjion O, Watson P et al., 2008. A hybrid individual: zonal travel cost model for estimating the consumer surplus of golfing in Colorado. journal of Sports Economics, 10(2): 155-167. doi: 10.1177/1527002508320136

Ma Jianying, Sun Xuegang, 2001. Review of studies on forest tourism resource evaluation. Journal of Gansu Agricultural University, 36(4): 357-363. (in Chinese)

Ma Zhong, 2006. Introduction of Environmental and Natural Resource Economics. Beijing: Higher Education Press. (in Chinese)

Mendes I, 2002. Travel and On Site Recreation Time: An Empirical Approach to Value the Recreation Benefits of Peneda-Gerês National Park. Lisbon: IATUR's 2002 Conference.

Preez M D, Hosking S, 2010. Estimating the recreational value of freshwater inflows into the Klein and Kwelera estuaries: an application of the zonal travel cost method. Water $S A, 36(5)$ : 553-561.

Walsh R G, Loomis J B, Gillman R A, 1984. Valuing option, existence, and bequest demands for wilderness. Land Economics, 60(1): 14-29. doi: 10.2307/3146089

Wang Huijuan, 2011. A brief talk of natural landscape aesthetics of Fuping Tianshengqiao scenic spot in Hebei Province. Tourism Overview, (7): 106-108. (in Chinese)

Willis K, Benson J, 1989. Recreational values of forests.
Forestry, 62(2): 93-110. doi: 10.1093/forestry/62.2.93-a

Willis K G, Garrod G, 1991. An individual travel: cost method of evaluating forest recreation. Journal of Agricultural Economics, 42(1): 33-42. doi: 10.1111/j.1477-9552.1991.tb00 330.x

Xie Zhengxian, Ma Zhong, 2006. Evaluating recreation value of Mount. Huang using travel cost method. Resources Science, 28(3): 128-136. (in Chinese)

Xue Dayuan, Bao Haosheng, Li Wenhua, 1999. A study on tourism value of biodiversity in Changbaishan mountain biosphere reserve in northeast China. Journal of Natural Resources, 14(2): 140-145. (in Chinese)

Yang W, Chang J, Xu B et al., 2008. Ecosystem service value assessment for constructed wetlands: a case study in Hangzhou, China. Ecological Economics, 68: 116-125. doi: 10.1016/j.ecolecon.2008.02.008

Yu Yang, Wang Erda, Zhao Ling et al., 2009. Documentation study of economic valuation on recreational tourism resources. East China Economic Management, 23(9): 140-145. (in Chinese)

Zhang Jinquan, 2007. The study of non use value evaluation of Huangshan mountain based on CVM. Shanghai: Shanghai Normal University. (in Chinese)

Zhang Xiaoli, Ma Li, Lu Xiaozhen et al., 2011. Research on the evaluation method of recreation value: a case study of Fengyangshan National Nature Reserve. China Population, Resources and Environment, 21(3): 213-216. (in Chinese) 